\title{
Investigation of Two-degree-of-freedom Parametric Oscillation by the Harmonic Balance Method
}

\author{
Masaru Ohta, Mitsuo Natsusaka, and Yoshinori Sakamoto \\ Hachinohe Inst. of Tech., 88-1, Obiraki, Myo, Hachinohe 031-8501, Japan
}

\begin{abstract}
We previously proposed a technique to analyze a planar parametric transformer using the harmonic balance method. The calculated characteristics of the transformer agreed approximately with the experimental ones. We analyze here the characteristics of two-degree-of-freedom parametric oscillation to confirm the validity of analysis of a parametric oscillation using the harmonic balance method. The characteristics of the relation between the input and output voltages and the phase of the two-degree-of-freedom parametric oscillation device were obtained using this method.
\end{abstract}

Key words: parametric oscillation, two-degree-of-freedom parametric oscillation, magnetic circuit model, harmonic balance method

\section{調波平衡法による 2 自由度のパラメトリック発振現象に関する検討}

\author{
太田勝・夏坂光男・坂本禎智
}

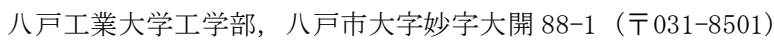

1. はじめに

パラメトリック発振を利用した機器には，過負荷保護機 能, 杂隹音ろ波機能, 変圧器のような出力を得る機器の場合 は定電圧特性など，実用上有利となる特長を有している. また，条件を満たしていれば，様々な形状でパラメトリッ ク発振を生じさせることが可能であり，立体的な磁路構造 の機器から平面磁路の機器まで様々な形状の機器が開発さ れている。しかし，パラメトリック発振現象は非線形振動 現象を利用しているため, 動作解析が容易ではなく, パラ メトリック発振を利用した機器の特性や安定性について 種々の検討が行われてきている 11$)$ 2).

筆者らは, これまでに平面磁路形パラメトリック変圧器 について形状や設計法について検討を行ってきた。 また, 設計法の確立を目的として, 磁気回路モデルとパラメトリ ック発振の基本回路から回路方程式を導出し, 調波平衡法 により動作解析を行った. その結果, 入出力電圧特性, 負 荷特性, 位相特性の実測值と計算值の傾向が一致し, 解析 方法の妥当性を確認している ${ }^{3) \sim 6)}$.

本論文では，これまでに検討してきた手法を，2自由度 のパラメトリック発振を利用した単相励磁入力三相パラメ トリックモータ 7)の回転子を除いた状態について適用し, 本解析方法の妥当性について検討を行った結果について報 告する.

\section{2. 基本構成と磁気回路モデル}

Fig.1 は本解析に使用した単相入力 3 相パラメトリック モータの回転子を除いた基本構成図である. 各寸法は, $a=$ $15 \mathrm{~mm}, b=5 \mathrm{~mm}, c=10 \mathrm{~mm}, d=42 \mathrm{~mm}, D_{\mathrm{s}}=100 \mathrm{~mm}$, 厚 さ $0.5 \mathrm{~mm}$ の無方向性ケイ素鋼鈑を 40 枚積層している. 磁 極は，それぞれ空間的に $60^{\circ}$ の位置に配置し，パラメトリ ック発振回路 2 系統を空間的に $120^{\circ}$ および $240^{\circ}$ となる

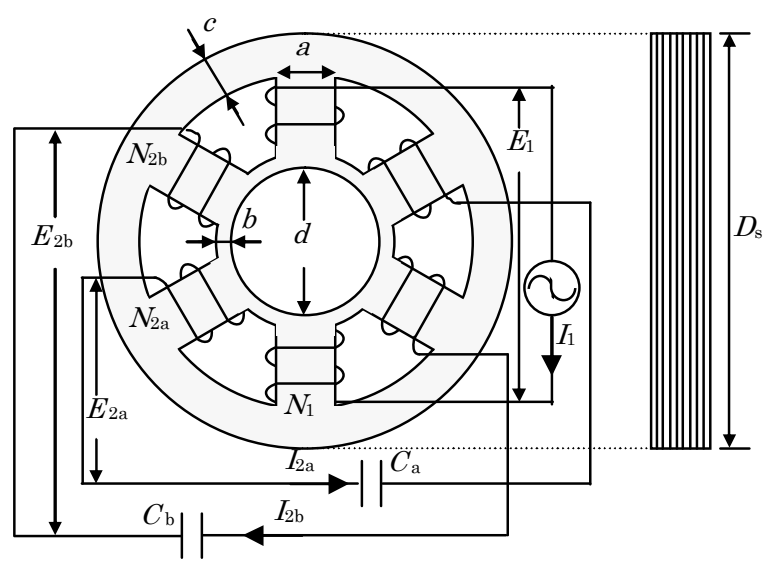

Fig. 1 Outline of structure.

ように設計されている. それぞれの磁極には, 励磁巻線 $N_{1}$, 共振巻線 $N_{2 \mathrm{a}}, N_{2 \mathrm{~b}}$ が施されている. それぞれの巻線数は $N_{1}=N_{2 \mathrm{a}}=N_{2 \mathrm{~b}}=1000$ turn として製作している. 励磁巻線に は交流電源, それぞれ共振巻線には, 同調用コンデンサ $C_{\mathrm{a}}$, $C_{\mathrm{b}}$ を接続している.

励磁巻線より励磁すると, 内側環状磁路は外側環状磁路 および磁極よりも細く設計されており，先に磁気飽和する ようになっている. 磁気飽和により共振側から見たインダ クタンスが周期的に変化し，この変化に対して同調用コン デンサ $C_{\mathrm{a}}, C_{\mathrm{b}}$ が同調してパラメトリック発振が生じる. パ ラメトリック発振の励磁側に対する位相差は, 理想的には $90^{\circ}$ となるが, 材質, 寸法, 励磁条件, 負荷の大きさ等に より $90^{\circ}$ 以上になる場合もある.

Fig.2 は解析に用いた磁気回路モデルである.磁極の磁気 抵抗を $R_{\mathrm{a}}$, 内側共通磁路の磁気抵抗を $R_{\mathrm{b}}$, 外側共通磁路 の磁気抵抗 $R_{\mathrm{c}}$, 励磁側および共振側の磁束を $\phi_{1}, \phi_{2 \mathrm{a}}, \phi_{2 \mathrm{~b}}$ としている. 


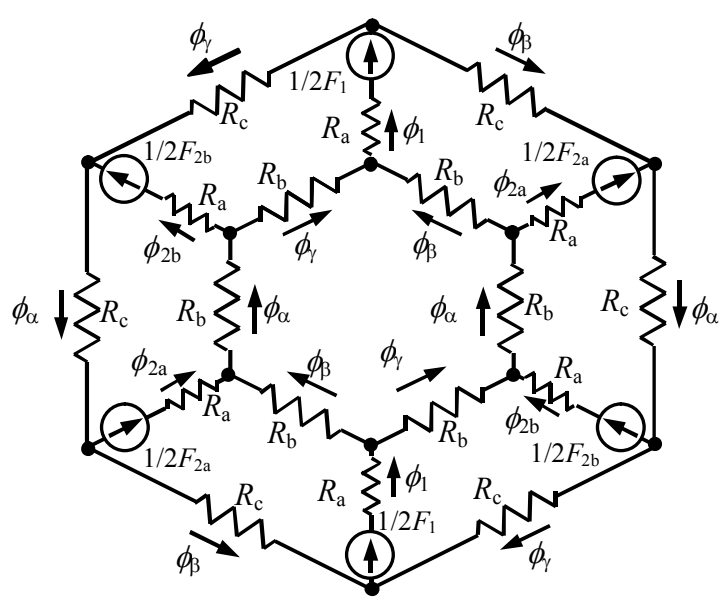

Fig. 2 Magnetic circuit model of two-degree-of-freedom parametric oscillation.

磁気抵抗の飽和特性をそれぞれ， $F_{\mathrm{a}}=f_{\mathrm{a}}(\phi), \quad F_{\mathrm{b}}=f_{\mathrm{b}}(\phi)$, $F_{\mathrm{c}}=f_{\mathrm{c}}(\phi)$ とすると, 起磁力 $F_{1}, F_{2 \mathrm{a}}, F_{2 \mathrm{~b}}$ は次のように表わ される。

$$
\begin{gathered}
F_{1}=N_{1} i_{1}=2 f_{\mathrm{a}}\left(\phi_{1}\right)+f_{\mathrm{b}}\left(\phi_{\alpha}\right)+f_{\mathrm{b}}\left(\phi_{\beta}\right)+f_{\mathrm{b}}\left(\phi_{\gamma}\right) \\
+f_{\mathrm{c}}\left(\phi_{\alpha}\right)+f_{\mathrm{c}}\left(\phi_{\beta}\right)+f_{\mathrm{c}}\left(\phi_{\gamma}\right) \\
F_{2 \mathrm{a}}=N_{2 \mathrm{a}} i_{2 \mathrm{a}}=2 f_{\mathrm{a}}\left(\phi_{2 \mathrm{a}}\right)+f_{\mathrm{b}}\left(\phi_{\alpha}\right)-f_{\mathrm{b}}\left(\phi_{\beta}\right)+f_{\mathrm{b}}\left(\phi_{\gamma}\right) \\
+f_{\mathrm{c}}\left(\phi_{\alpha}\right)-f_{\mathrm{c}}\left(\phi_{\beta}\right)+f_{\mathrm{c}}\left(\phi_{\gamma}\right) \\
F_{2 \mathrm{~b}}=N_{2 \mathrm{~b}} i_{2 \mathrm{~b}}=2 f_{\mathrm{a}}\left(\phi_{2 \mathrm{~b}}\right)+f_{\mathrm{b}}\left(\phi_{\alpha}\right)+f_{\mathrm{b}}\left(\phi_{\beta}\right)-f_{\mathrm{b}}\left(\phi_{\gamma}\right) \\
+f_{\mathrm{c}}\left(\phi_{\alpha}\right)+f_{\mathrm{c}}\left(\phi_{\beta}\right)-f_{\mathrm{c}}\left(\phi_{\gamma}\right)
\end{gathered}
$$

ただし $, \phi_{\alpha}=1 / 2\left(\phi_{1}+\phi_{2 \mathrm{a}}+\phi_{2 \mathrm{~b}}\right), \quad \phi_{\beta}=1 / 2\left(\phi_{1}-\phi_{2 \mathrm{a}}+\phi_{2 \mathrm{~b}}\right)$, $\phi_{\gamma}=1 / 2\left(\phi_{1}+\phi_{2 \mathrm{a}}-\phi_{2 \mathrm{~b}}\right)$ とする.

また，ヒステリシスを無視した磁気抵抗 $R_{\mathrm{a}}, R_{\mathrm{b}}, R_{\mathrm{c}}$ の 飽和特性は次式のように磁束の 9 次式で近似する.

$$
\begin{aligned}
& 2 f_{\mathrm{a}}(\phi)=a_{1} \phi+a_{3} \phi^{3}+a_{5} \phi^{5}+a_{7} \phi^{7}+a_{9} \phi^{9} \\
& f_{\mathrm{b}}(\phi)=b_{1} \phi+b_{3} \phi^{3}+b_{5} \phi^{5}+b_{7} \phi^{7}+b_{9} \phi^{9} \\
& f_{\mathrm{c}}(\phi)=c_{1} \phi+c_{3} \phi^{3}+c_{5} \phi^{5}+c_{7} \phi^{7}+c_{9} \phi^{9}
\end{aligned}
$$

飽和特性の係数 $a_{\mathrm{i}}, b_{\mathrm{i}}, c_{\mathrm{i}}(\mathrm{i}=1,3,5 ， 7 ， 9)$ は，材料の B-H 特性, 磁心の磁路長, および断面積より求めことがで きる.

\section{3. 解析方法}

Fig.3 は共振側の回路であり, 本機器では 2 自由度のパ ラメトリック発振を生じさせるため 2 つの回路が存在する. ここで, 巻線の抵抗をそれぞれ $r_{2 \mathrm{a}}, r_{2 \mathrm{~b}}$, 負荷抵抗を $R_{\mathrm{a}}$, $R_{\mathrm{b}}$ とすると次式が得

られる。

$$
\begin{aligned}
& \mathrm{d}^{2} \phi_{2 \mathrm{a}} / \mathrm{d} t^{2}+\left(1 / C_{\mathrm{a}} R_{\mathrm{a}}\right)\left(\mathrm{d} \phi_{2 \mathrm{a}} / \mathrm{d} t\right) \\
& \quad+\left(r_{2 \mathrm{a}} / N_{2 \mathrm{a}}\right)\left(\mathrm{d} i_{2 \mathrm{a}} / \mathrm{d} t\right)+\left(1 / C_{\mathrm{a}} N_{2 \mathrm{a}}\right)\left(r_{2 \mathrm{a}} / R_{\mathrm{a}}+1\right) i_{2 \mathrm{a}}=0 \\
& \mathrm{~d}^{2} \phi_{2 \mathrm{~b}} / \mathrm{d} t^{2}+\left(1 / C_{\mathrm{b}} R_{\mathrm{b}}\right)\left(\mathrm{d} \phi_{2 \mathrm{~b}} / \mathrm{d} t\right) \\
& \quad+\left(r_{2 \mathrm{~b}} / N_{2 \mathrm{~b}}\right)\left(\mathrm{d} i_{2 \mathrm{~b}} / \mathrm{d} t\right)+\left(1 / C_{\mathrm{a}} N_{2 \mathrm{~b}}\right)\left(r_{2 \mathrm{~b}} / R_{\mathrm{b}}+1\right) i_{22 \mathrm{~b}}=0
\end{aligned}
$$

モータの場合, 負荷抵抗により出力を取る必要がないが,

ここでは, 三相変圧器の可能性も考慮して負荷抵抗を接続 している.これらの式に式(2)，(3)，(4)，（5)，(6)を代入し て整理すると回路方程式が得られる.

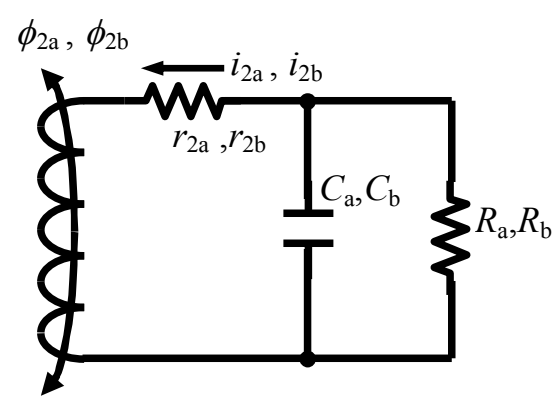

Fig. 3 Secondary circuit of a device.

$$
\begin{aligned}
& \mathrm{d}^{2} \phi_{2 \mathrm{a}} / \mathrm{d} t^{2}+\left(1 / C_{\mathrm{a}} R_{\mathrm{a}}\right)\left(\mathrm{d} \phi_{2 \mathrm{a}} / \mathrm{d} t\right) \\
& +\left(r_{2} \mathrm{a} / N_{2 \mathrm{a}^{2}}\right)\{ \\
& \mathrm{d}\left(a_{1} \phi_{2 \mathrm{a}}+a_{3} \phi_{2 \mathrm{a}^{3}}+a_{5} \phi_{2} \mathrm{a}^{5}+a_{7} \phi_{2} \mathrm{a}^{7}+a_{9} \phi_{2} \mathrm{a}^{9}\right. \\
& +p_{1} \phi_{\alpha}+p_{3} \phi_{\alpha}^{3}+p_{5} \phi_{\alpha}^{5}+p_{7} \phi_{\alpha}{ }^{7}+p_{9} \phi_{\alpha}{ }^{9} \\
& -p_{1} \phi_{\beta}-p_{3} \phi_{\beta}{ }^{3}-p_{5} \phi_{\beta}{ }^{5}-p_{7} \phi_{\beta}{ }^{7}-p_{9} \phi_{\beta}{ }^{9} \\
& \left.\left.+p_{1} \phi_{\gamma}+p_{3} \phi_{\gamma}^{3}+p_{5} \phi_{\gamma}^{5}+p_{7} \phi_{\gamma}^{7}+p_{9} \phi_{\gamma}^{9}\right) / \mathrm{dt}\right\} \\
& +\left(1 / C_{\mathrm{a}} N_{2 \mathrm{a}}{ }^{2}\right)\left(r_{2 \mathrm{a}} / R_{\mathrm{a}}+1\right)( \\
& a_{1} \phi_{2 \mathrm{a}}+a_{3} \phi_{2 \mathrm{a}}{ }^{3}+a_{5} \phi_{2 \mathrm{a}^{5}}+a_{7} \phi_{2 \mathrm{a}^{7}}+a_{9} \phi_{2 \mathrm{a}^{9}} \\
& +p_{1} \phi_{\alpha}+p_{3} \phi_{\alpha}^{3}+p_{5} \phi_{\alpha}^{5}+p_{7} \phi_{\alpha}{ }^{7}+p_{9} \phi_{\alpha}{ }^{9} \\
& -p_{1} \phi_{\beta}-p_{3} \phi_{\beta}{ }^{3}-p_{5} \phi_{\beta}{ }^{5}-p_{7} \phi_{\beta}{ }^{7}-p_{9} \phi_{\beta}{ }^{9} \\
& \left.+p_{1} \phi_{\gamma}+p_{3} \phi_{\gamma}^{3}+p_{5} \phi_{\gamma}^{5}+p_{7} \phi_{\gamma}^{7}+p_{9} \phi_{\gamma}^{9}\right)=0 \\
& \mathrm{~d}^{2} \phi_{2 \mathrm{~b}} / \mathrm{d} t^{2+}\left(1 / C_{\mathrm{b}} R_{\mathrm{b}}\right)\left(\mathrm{d} \phi_{2 \mathrm{~b}} / \mathrm{d} t\right) \\
& +\left(r_{2 b} / N_{2 b}{ }^{2}\right)\{ \\
& \mathrm{d}\left(a_{1} \phi_{2 \mathrm{~b}}+a_{3} \phi_{2 \mathrm{~b}^{3}}+a_{5} \phi_{2 \mathrm{~b}^{5}}+a_{7} \phi_{2} \mathrm{~b}^{7}+a_{9} \phi_{2 \mathrm{~b}^{9}}\right. \\
& +p_{1} \phi_{\alpha}+p_{3} \phi_{\alpha}{ }^{3}+p_{5} \phi_{\alpha}{ }^{5}+p_{7} \phi_{\alpha}{ }^{7}+p_{9} \phi_{\alpha}{ }^{9} \\
& +p_{1} \phi_{\beta}+p_{3} \phi_{\beta}^{3}+p_{5} \phi_{\beta}{ }^{5}+p_{7} \phi_{\beta}{ }^{7}+p_{9} \phi_{\beta}{ }^{9} \\
& \left.\left.-p_{1} \phi_{\gamma}-p_{3} \phi_{\gamma}^{3}-p_{5} \phi_{\gamma}^{5}-p_{7} \phi_{\gamma}^{7}-p_{9} \phi_{\gamma}^{9}\right) / \mathrm{dt}\right\} \\
& +\left(1 / C_{\mathrm{b}} N_{2 \mathrm{~b}} 2\right)\left(r_{2 \mathrm{~b}} / R_{\mathrm{b}}+1\right)( \\
& a_{1} \phi_{2 \mathrm{~b}}+a_{3} \phi_{2 \mathrm{~b}^{3}}+a_{5} \phi_{2 \mathrm{~b}^{5}}+a_{7} \phi_{2 \mathrm{~b}^{7}}+a_{9} \phi_{2 \mathrm{~b}^{9}} \\
& +p_{1} \phi_{\alpha}+p_{3} \phi_{\alpha}^{3}+p \phi_{\alpha}{ }^{5}+p_{7} \phi_{\alpha}{ }^{7}+p_{9} \phi_{\alpha}{ }^{9} \\
& +p_{1} \phi_{\beta}+p_{3} \phi_{\beta}{ }^{3}+p_{5} \phi_{\beta}{ }^{5}+p_{7} \phi_{\beta}{ }^{7}+p_{9} \phi_{\beta}{ }^{9} \\
& \left.-p_{1} \phi_{\gamma}-p_{3} \phi_{\gamma}^{3}-p_{5} \phi_{\gamma}^{5}-p_{7} \phi_{\gamma}^{7}-p_{9} \phi_{\gamma}^{9}\right)=0
\end{aligned}
$$

ただし $, p_{1}=b_{1}+c_{1}, p_{3}=b_{3}+c_{3}, p_{5}=b_{5}+c_{5}, p_{7}=b_{7}+c_{7}, p_{9}=b_{9}+c_{9}$ とする.

ここで, 電源電圧を $e_{1}=\sqrt{2} E_{1} \sin \omega t$ として, $N_{1}$ の巻線抵 抗が小さいものとして無視すれば励磁側の磁束 $\phi_{1}$ は次式で 近似される。

$$
\phi_{1}=-\Phi_{1} \cos \omega t\left(\Phi_{1}=\sqrt{2} E_{1} / \omega N_{1}\right)
$$

また，共振側電圧の波形 $E_{2 a} ， E_{2 \mathrm{~b}}$ が正弦波状であること から，共振側の磁束 $\phi_{2 \mathrm{a}}, \phi_{2 \mathrm{~b}}$ を次のように仮定する.

$$
\begin{array}{ll}
\phi_{2 \mathrm{a}}=-\Phi_{2 \mathrm{a}} \cos \left(\omega t+\varphi_{\mathrm{a}}\right) & \left(\Phi_{2 \mathrm{a}}=\sqrt{2} E_{2 \mathrm{a}} / \omega N_{2 \mathrm{a}}\right) \\
\phi_{2 \mathrm{~b}}=-\Phi_{2 \mathrm{~b}} \cos \left(\omega t+\varphi_{\mathrm{b}}\right) & \left(\Phi_{2 \mathrm{~b}}=\sqrt{2} E_{2 \mathrm{~b}} / \omega N_{2 \mathrm{~b}}\right)
\end{array}
$$

式(11)，(12)，(13)を式(9)，(10)に代入して，基本波のみを 考慮した調波平衡法を適用して，得られた式を満たすよう な振幅 $\Phi_{2 \mathrm{a}}, \Phi_{2 \mathrm{~b}}$ と位相 $\varphi_{\mathrm{a}}, \varphi_{\mathrm{b}}$ を決定すれば, 磁束 $\phi_{2 \mathrm{a}}, \phi_{2 \mathrm{~b}}$ を求めることができる.

\section{4. 回路定数と計算結果}

Table 1 に数值計算に用いた係数を示す. 飽和特性の係数 
Table 1 Circuit constants.

\begin{tabular}{|c|c|c|c|}
\hline$a_{1}(\mathrm{~A} / \mathrm{Wb})$ & $1.04 \times 10^{3}$ & $c_{1} \quad(\mathrm{~A} / \mathrm{Wb})$ & $3.42 \times 10^{3}$ \\
\hline$a_{3}\left(\mathrm{~A} / \mathrm{Wb}^{3}\right)$ & $-1.65 \times 10^{10}$ & $c_{3}\left(\mathrm{~A} / \mathrm{Wb}^{3}\right)$ & $-1.22 \times 10^{11}$ \\
\hline$a_{5}\left(\mathrm{~A} / \mathrm{Wb}^{5}\right)$ & $2.72 \times 10^{17}$ & $c_{5}\left(\mathrm{~A} / \mathrm{Wb}^{5}\right)$ & $4.52 \times 10^{18}$ \\
\hline$a_{7}\left(\mathrm{~A} / \mathrm{Wb}^{7}\right)$ & $-1.96 \times 10^{24}$ & $c_{7}\left(\mathrm{~A} / \mathrm{Wb}^{7}\right)$ & $-7.33 \times 10^{25}$ \\
\hline$a_{9}\left(\mathrm{~A} / \mathrm{Wb}^{9}\right)$ & $5.45 \times 10^{30}$ & $c_{9}\left(\mathrm{~A} / \mathrm{Wb}^{9}\right)$ & $4.60 \times 10^{32}$ \\
\hline$b_{1}(\mathrm{~A} / \mathrm{Wb})$ & $3.57 \times 10^{3}$ & $r_{2 a}, r_{2 b}(\Omega)$ & 10 \\
\hline$b_{3}\left(\mathrm{~A} / \mathrm{Wb}^{3}\right)$ & $-5.09 \times 10^{11}$ & $N_{1}$ & 1000 \\
\hline$b_{5}\left(\mathrm{~A} / \mathrm{Wb}^{5}\right)$ & $7.56 \times 10^{19}$ & $N_{2 \mathrm{a}}$ & 1000 \\
\hline$b_{7}\left(\mathrm{~A} / \mathrm{Wb}^{7}\right)$ & $-4.90 \times 10^{27}$ & $N_{2 b}$ & 1000 \\
\hline$b_{9}\left(\mathrm{~A} / \mathrm{Wb}^{9}\right)$ & $1.23 \times 10^{35}$ & $f(\mathrm{~Hz})$ & 50 \\
\hline
\end{tabular}

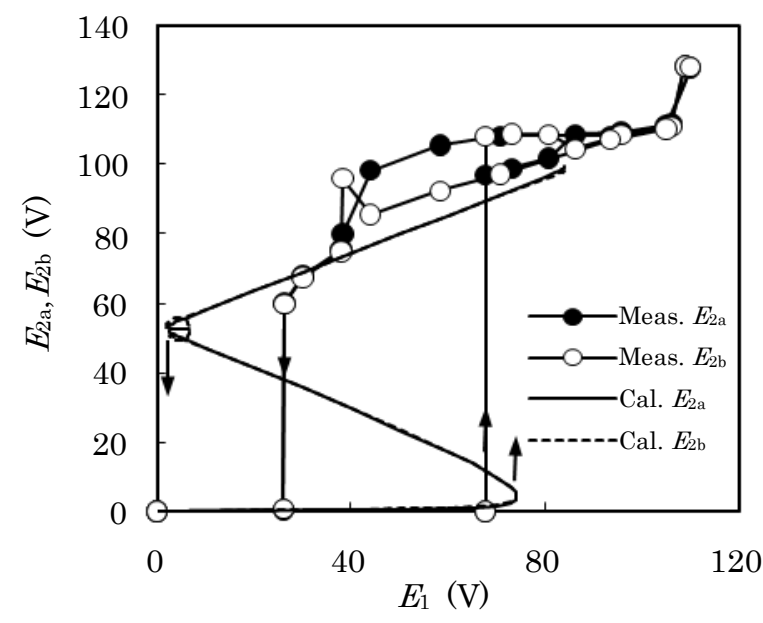

(a) $C_{\mathrm{a}}=C_{\mathrm{b}}=20 \mu \mathrm{F}$

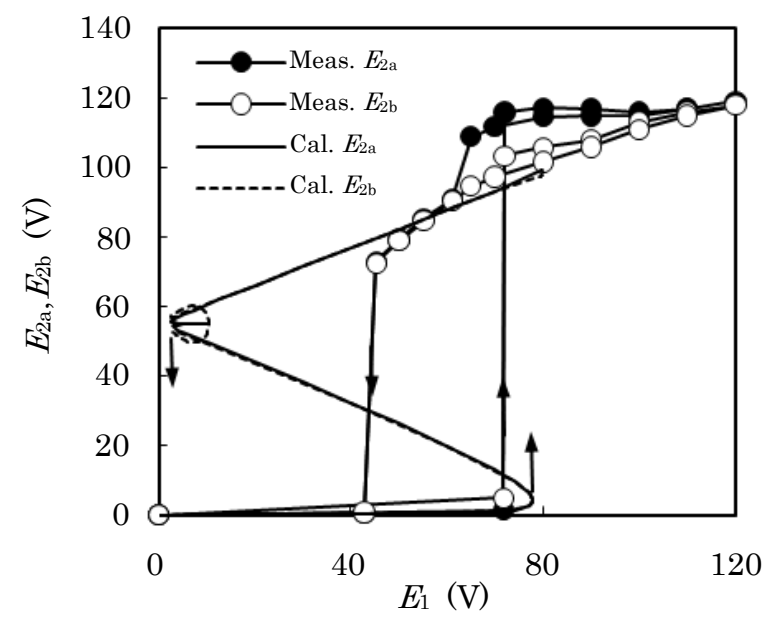

(b) $C_{\mathrm{a}}=C_{\mathrm{b}}=30 \mu \mathrm{F}$

Fig. 4 Relations between the voltages $E_{1}$ and the resonance voltages $E_{2 \mathrm{a}}$ and $E_{2 \mathrm{~b}}$.

$a_{\mathrm{i}}, b_{\mathrm{i}}, c_{\mathrm{i}}(\mathrm{i}=1,3,5,7,9)$ は, 磁性材料の B-H 特性, 磁心 の磁路長, および断面積より求めており, 各巻線抵抗は実
測值を使用している。

Fig. 4 は, 励磁電圧 $E_{1}$ と共振側電圧 $E_{2 \mathrm{a}}, E_{2 \mathrm{~b}}$ の関係を表 す入出力電圧特性の実測值と計算值である. 測定にはディ ジタルマルチメータを使用しており, 励磁電圧 $E_{1}$ の值によ っては，波形が歪む場合があるため，測定誤差が大きい部 分がある。また，計算值は $\mathrm{S}$ 字状になっており， $E_{1}$ に対 して解が 1 つの部分と 3 つの部分が存在する. この変わり 目が発振確立および停止の電圧となり，矢印の向きでそれ ぞれを表している。

励磁電圧 $E_{1}$ を増大させていくと, ある電圧でパラメトリ ック発振が確立し, 共振電圧 $E_{2 \mathrm{a}}, E_{2 \mathrm{~b}}$ が急激に上昇する. 次にパラメトリック発振確立後, 励磁電圧を減少させると 発振確立電圧よりも低い電圧值で発振が停止し，共振側電 圧 $E_{2 \mathrm{a}}, E_{2 \mathrm{~b}}$ は急激に減少する。このように入出力電圧特性 が履歴特性となっており, パラメトリック発振を利用した 機器で確認できる特性となっている.

また, パラメトリック発振確立後, さらに励磁電圧を増 大させると, 平面磁路形パラメトリック変圧器ではほぼ一 定の電圧值を保ち, 平面磁路形パラメトリックモータの回 転子を取り除いた状態では共振側電圧が減少する傾向にあ るが 8), 本機器では増加する傾向にあることが分かる.

同調用コンデンサ $C_{\mathrm{a}}, C_{\mathrm{b}}$ の容量によっては, 不安定現象 や基本波以外の周波数で発振する場合がある。同調用コン デンサ $C_{\mathrm{a}}=C_{\mathrm{b}}=20 \mu \mathrm{F}$ の実測值における $E_{1}=100 \mathrm{~V}$ 付近か ら共振側電圧が急激に上昇しているが，これは基本波以外 での発振によるものである.また， $E_{1}=50 \mathrm{~V}$ 付近でも不安 定現象を確認している. $C_{\mathrm{a}}=C_{\mathrm{b}}=30 \mu \mathrm{F}$ においては，このよ うな不安定現象および基本波以外での発振現象などは発生 せず全領域で安定している.

入出力電圧特性の $C_{\mathrm{a}}=C_{\mathrm{b}}=20 \mu \mathrm{F}$ の計算值において, $E_{1}$ $=70 \mathrm{~V}$ 付近で発振確立し, $E_{1}=2 \mathrm{~V}$ 付近で発振が停止して おり，パラメトリック発振の特長である履歴特性となって いることが分かる．また計算值では，共振側電圧 $E_{2 \mathrm{a}}, E_{2 \mathrm{~b}}$ はほぼ同様の傾向にあり, 重なっている部分がほとんどで あるが，パラメトリック発振確立後の電圧值に多少の変化 がみられる。ここで， $E_{1}=80 \mathrm{~V}$ 付近で共振側電圧の值が止 まっているが，これはここで計算を終了したわけではなく， これ以上の実数解をみつけることができなかったためであ る.

発振停止電圧付近で円を描くような計算結果が得られて いるが，これは飽和特性の係数を求める過程において, B-H 特性の線形部分の近似が線形になっておらず，わずかに変 化している部分が影響しているのではないかと考えている. 式 (4)，（5)，（6）のように各磁気抵抗の飽和特性を 9 次式 で近似しているが，Table1 の係数を見ても分かるように負 の係数があるため, 線形部分や磁気飽和の浅い部分で変化 が生じ，このような結果が生じたものと考えている。

実測值と計算值を比較してみると，パラメトリック発振 確立電圧は近い值となっているが，停止電圧においては大 幅な相違がみられる. 平面磁路形パラメトリック変圧器の 
解析においてもこのような傾向にあり，損失を考慮してい ない点と漏れ磁束等などが考慮されていないためにこのよ うな結果になったと考えられる.

Fig.5 にパラメトリック発振時の $E_{1}=80 \mathrm{~V}$ における励磁 側および共振側の波形の実測值および計算值を示す。実測 值の波形は励磁側の波形に対して共振側の電圧の位相差が それぞれ $10^{\circ} ， 20^{\circ}$ 程度生じていることが確認できる.

調波平衡法を使った本手法では，パラメトリック発振に よって共振側電圧が正弦波状になると仮定して解析を行っ ているため, 励磁側から共振側一流入する磁束による波形 の歪みや過飽和による高調波成分が多い場合には誤差が増 大寸る可能性があり，これに対応するためには，基本波以 外も考慮に入れて検討を行う必要がある.

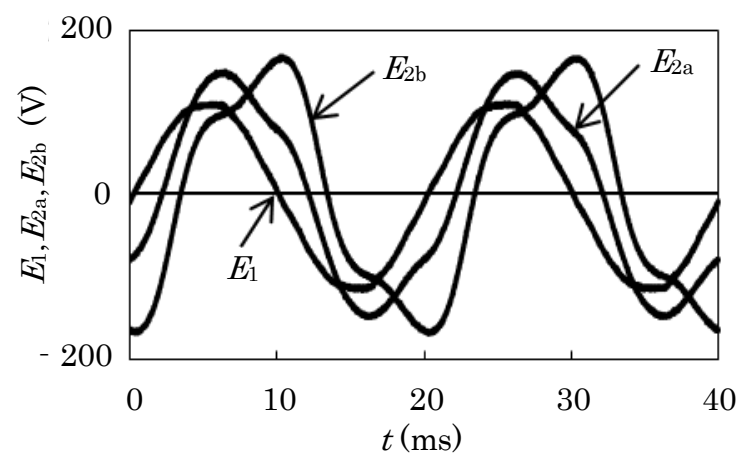

(a) Measured.

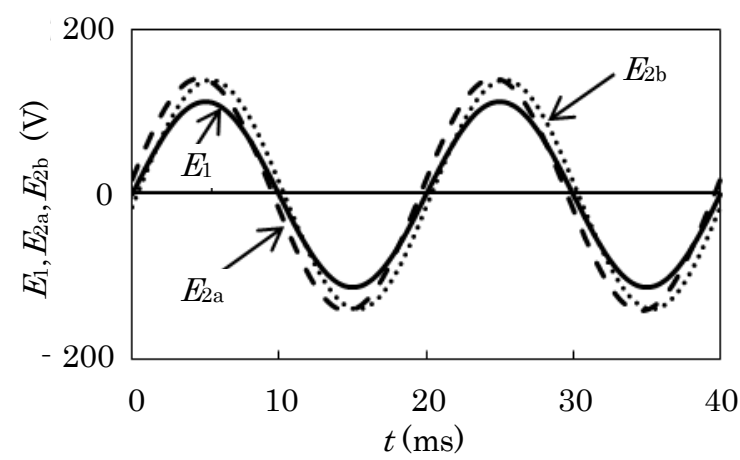

(b) Calculated.

Fig.5 Two-degree-offfreedom parametric oscillation waveforms.
計算值では，実測值ほど位相差が生じておらず，また波 形も正弦波として仮定しているため, 歪みなどは発生しな い.

\section{5. まとめ}

調波平衡法を用いて 2 自由度のパラメトリック発振を使 つた機器の解析を行った。 その結果入出力電圧特性の傾向 が一致するが，発振停止電圧についてはこれまで検討を行 ってきた平面磁路形パラメトリック変圧器と同様に相違が あり，損失等をより細かく考慮する必要があることが明ら かになった. 特に 2 自由度のパラメトリック発振の場合, 2 系統が発振時にそれぞれ影響をあたえ波形が歪む場合があ り，基本波のみを考慮した調波平衡法では誤差が生じる可 能性があるため、高調波を含めた解析が必要であると考え られる.また，パラメトリック発振周波数についても，基 本波での発振のみを考慮していたが，実測では 3 倍周波の 発振現象も発生しており, この点についても検討する必要 がある。

本研究の成果は，今後パラメトリック発振を利用したデ バイスの製作に役に立つ有用な成果であると思われる.

\section{References}

1) M.yoshida, M. ohta, M. Natsusaka, and Y.Sakamoto: J. Magn. Soc. Jpn., 34, 3, pp. 416-421 (2010).

2) K. Tajima, M. Hattori, T. Miyaji, T. Sato, and Y. Sakamoto: $J$. Magn. Soc. Jpn., 29, 6, pp.680-685 (2005).

3) M.ohta, Y.Sakamoto, M. Natsusaka, and K.Murakami: J. Magn. Soc. Jpn., 22, 4, pp. 717-720 (1998).

4) M.ohta, Y.Sakamoto, and K.Murakami: J. Magn. Soc. Jpn., 23, 4, pp. 1501-1504 (1999).

5) M.ohta, Y.Sakamoto, and K.Murakami: J. Magn. Soc. Jpn., 24, 4-2, pp. 807-810 (2000).

6) M.ohta, and Y.Sakamoto: J. Magn. Soc. Jpn., 25, 4-2, pp. 1027 -1030 (2001).

7) T. Yashima, T. Hiwatashi, T. Ohkubo, M. Ohta, M. Natsusaka, and Y. Sakamoto: J. Magn. Soc. Jpn., 26, No.4, pp. 673-676 (2002).

8) Y. Sakamoto, M. Ohkubo, and, M. Natsusaka: T.IEE Japan, Mag-00-102 (2000)

2010年10月20日受理， 2011年2月1日採録 